\title{
The Effectiveness of the PLISSIT Model in Solving Postpartum Sexual Problems Experienced by Women
}

\author{
By Fatma Yörük* \\ Zekiye Karaçam ${ }^{\dagger}$
}

The aim of this study was to evaluate the effectiveness of the PLISSIT [Permission (P), Limited Information (LI), Specific Suggestions (SS) and Intensive Therapy (IT)] model in dealing with postpartum sexual problems. This was a quasi-experimental study with a pretest, a post-test and a control group made with 123 women (intervention $=61$; control $=62$ ). Before the application of the PLISSIT Model intervention plan, $77.0 \%$ of the women in the intervention group and $71.0 \%$ of the women in the control group had statistically similar 12 points or above scores of Arizona Sexual Experiences Scale-female form and sexual problems. After the application of the PLISSIT Model intervention plan, the women in the intervention group (60.7\%) experienced statistically significant sexual problems according to the Arizona Sexual Experiences Scale-female form than the women in the control group (77.4\%). This study revealed that the PLISSIT Model intervention plan reduced the postpartum sexual problems experienced by women.

Keywords: Nurse, Nursing care, PLISSIT Model, Postpartum period, Sexual problems.

\section{Introduction}

A woman's sexual function is affected by factors such as puberty, birth and menopause as well as psychologic, social, economic, political, cultural, ethical, legal, religious spiritual and biologic attributes such as age; and many other factors springing from sexual tendencies (Abdol et al. 2009, Botros et al. 2006, Johnson 2011). During pregnancy, postpartum, menopause and old age; whether a woman's sexual desire and sexual activities continue depends on the existence of a sexual partner and his sexual functions, the quality of the partner's sexual relations, and the general health of the couple (Lamont and Hamilton 2012). The World Health Organisation emphasises that paying attention to sexual health is an important issue. Also it gives importance to focusing on sexuality during the development of the woman's health and wellbeing, and to the integration of this service into primary health care (World Health Organization 2004).

Most women attempt to return to their sexual lives within 8-12 weeks after delivery, but it can take up to a year before they can experience sexual intercourse the way it used to be before pregnancy. Postpartum challenges related to sexual intercourse can continue for three months on the average (111 months). It is realised from this study that the sexual function of women after delivery is worse when compared to what it used to be before delivery as

\footnotetext{
${ }^{*}$ Nurse, Akdeniz University Hopital, Cardiovascular Surgery Clinic, Turkey.

$\dagger$ Professor, Adnan Menderes University Aydın School of Health, Division of Midwifery, Turkey.
} 
the incidence of sexual dysfunction in adults which is 19-63\% (Hisasue et al. 2005, Oboro and Tabowei 2002) increases up to 34-91\% in women in the postpartum period and seems to vary over a wide range (Olsson et al. 2005, Williams et al. 2007). Sexual problems are experienced intensely particularly during the first three months of the postpartum period (Barrett et al. 2000, Xu et al. 2003). Barrett et al. (2000) notified that although a majority of women return to sexual activities within the first three months of the postpartum period; $83 \%$ of these women experience sexual problems and while this rate drops to $64 \%$ in the sixth month, $38 \%$ are never able to return to it at the the level it used to be before birth. Serati et al. (2010) also, in the review study incuded 48 studies, reported that breast-feeding, dyspareunia, and malfunctions of the pelvic girdle delay one's return to sexual life after delivery.

A limited number of studies relevant to sexual life are found in Turkey. According to a study carried out using the Arizona sexual life scale, $83 \%$ of women during the first year of the postpartum period experience sexual problems (Karaçam 2008). Using this same scale in a research involving 230

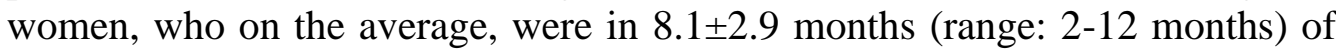
the postpartum perioid; it is informed that $38.3 \%$ of women before conception, $33.0 \%$ during pregnancy and $91.3 \%$ after delivery have sexual problems (Acele and Karaçam 2012). In another study involving 391 primiparas who had undergone vaginal delivey, it is reported that $34.8 \%$ of women before conception, $38.9 \%$ during pregnancy and $28.9 \%$ during the postpartum period experience dyspareunia (Karaçam and Çalışır 2012). Still in another research involving 35 women, it is reported that 4 of these women had not returned to sexual intercourse, their sexual life was affected by the following: inability to be alone $(n=34 / 35)$, insufficient time $(n=32 / 35)$, the baby's sleeplessness $(n=32 / 35)$, perineal discomfort $(n=30 / 35)$, lack of sexual desire $(n=28 / 35)$, fatigue $(n=27 / 35)$, discomforts in the breast $(n=16 / 35)$ and their partner's response $(n=3 / 35)$ (Şahin 2009). It is shown in these studies how sexual problems during the postpartum period, as compared to other periods, are more intense and widespread.

The sexual function of a woman during the postpartum period can be affected by many conditions. These include the mother's age, her level of education, the duration of marriage or the relationship with her partner, sexual problems before and during pregnancy, type of birth, breast-feeding, psychological problems and perineal traumas (Gibbsons et al. 2010, Hipp et al. 2012, Holanda et al. 2014, Johnson 2011, Lee and Tsai 2012, Salim and Gualda 2010, Shirvani et al. 2010). Fatigue, sleeplessness, some stressors such as childcare which is highly time consuming, hormonal changes (reduction of oestrogen-progesteron level and increase in prolactin etc.) and changes in the woman's body image during the postpartum period are reasons for reduced interest in sexual life and the reduced frequency of sexual relations (Olsson et al. 2005, Brtnicka et al. 2009). In addition, a number of women during the postpartum period experience dyspareunia due to reduced slickness in the vagina resulting from a low level of oestrogen (Abdool et al. 2009, Barrett et al. 2000, Handa 2006). Breastfeeding mothers may have decreased sexual 
desire owing to change in hormonal levels and suffer from dyspareunia because of vaginal dryness.

The issue of sexual life and sexual function is a topic which is tabooed in Turkey and encounters difficulties when brought up by health personnel. However, there are important responsilities of nurses on this topic. Aims postpartum care given by nurses is to strengthen the sexual health of the woman, encourage the expression of sexual problems, define the reasons and characteristics of sexual problems and implement interventions regarding problems defined. Nurses can plan and carry out protective and developmentary initiatives aimed at the sexual health of a woman, make early diagnoses, provide counselling for the treatment of existing problems and refer to them when necessary.

While diagonosing and making a care plan for postpartum sexual problems, nurses can benefit from the PLISSIT Model which provides a comprehensive and conceptual setting. The model was developed by Annon (1981) for effective discussions relating to sexual life between health personnel and an individual and also for the analysis of sexual problems. The PLISSIT model in collaboration with examining the individual, understanding their decisions and showing respect; supports the role of counselling in dealing with sexual problems. This model consists of four stages. These include PPermission, LI-Limited Information SS-Specific Suggestions and IT-Intensive Therapy. By applying the first three stages of this model, $80-90 \%$ of sexual problems can be solved. Annon (1981) informs that $70 \%$ of all sexual problems at the Permission stage can be solved and hence advocates the necessity of permitting an individual to explain their sexual worries and anxieties. This model can be applied at anytime to an individual where appropriate and in different situations (Annon 1981).

In studies which have been done early on, it was shown that the PLISSIT model had positive effects on the individuals, at different stages of life and in different circumstances, to whom it was applied and on their sexual functions (Ayaz and Kubilay 2008, Chun 2011, Cleary et al. 2012, Jaarsma et al. 2010, Ju-Hee 2013, Lara et al. 2008, Tütüncü 2009). This provoked the thought that the structure and features could be effecive in solving postpartum sexual problems. Consequentially, this study has been done to evaluate the effectiveness in using the PLISSIT model to solve postpartum sexual problems among women. The hypothesis, therefore, for this study is that the PLISSIT Model intervention plan used by nurses is effective in reducing sexual problems during the postpartum period.

\section{Methods}

Study Design

This was a quasi-experimental study with a pre-test, a post-test and a controlled group. The research was carried out between March 2011 and 
September 2013 in regions affiliated to Antalya Kepez no. 17 (Dr. Selattin Topçu) Family Health Centre and No. 18 Culture Family Health Centre. These two family centres were selected because of their proximity to each other from a socio-demographic point of view, their availability of individuals with similar status as well as families with different socio-economic statuses. Because women generally return to sexual life during the $1.5-2^{\text {nd }}$ month of the postpartum period and sexual problems are frequently encountered during the $3-12^{\text {th }}$ month; women within their $3-12^{\text {th }}$ month of the postpartum period were selected for the research.

\section{Study Participants}

The minimum number of individuals to be sampled was calculated with a $95 \%$ confidence interval and an $80 \%$ level of effect, and it was found that a total of 123 people were necessary for the research. From of the 123 people selected out of 640 women using the systematic sampling method, 61 and 62 women were randomly placed into the intervention group and control group respectively. There would be more the possibility of case losses because the research was made during the summer time, for each woman who was included in the research sample, a reserve was selected again by using the systematic sampling method. Women with ages 18-40, elementary school eduction or above and within 3-12 months of the postpartum period were included to this study. Women that had been diagnosed with a psychological and sexual disorder, who their spouses were diagnosed with a psychological and sexual disorder, who were pregnant, who had not returned to their sexual life after delivery, and could not be found in their home during the home visits, were excluded from the study. Women without formal education to enable them to personally fill the the Arizona Sexual Experience Scale-Female Form and the Sexual Quality of Life Scale-Female Form were also exempted from the reseach. Women who, based on the Arizona Sexual Experience Scale-Female Form, were separated from their spouses or who were considered sexually inactive because of a questionable sexual life in the previous week were excluded during sampling. Information regarding the inclusion and exclusion of women during the sampling for the study is given in Figure 1. 
Figure 1. Data on Women who Qualified for Sampling and those who Were Sampled

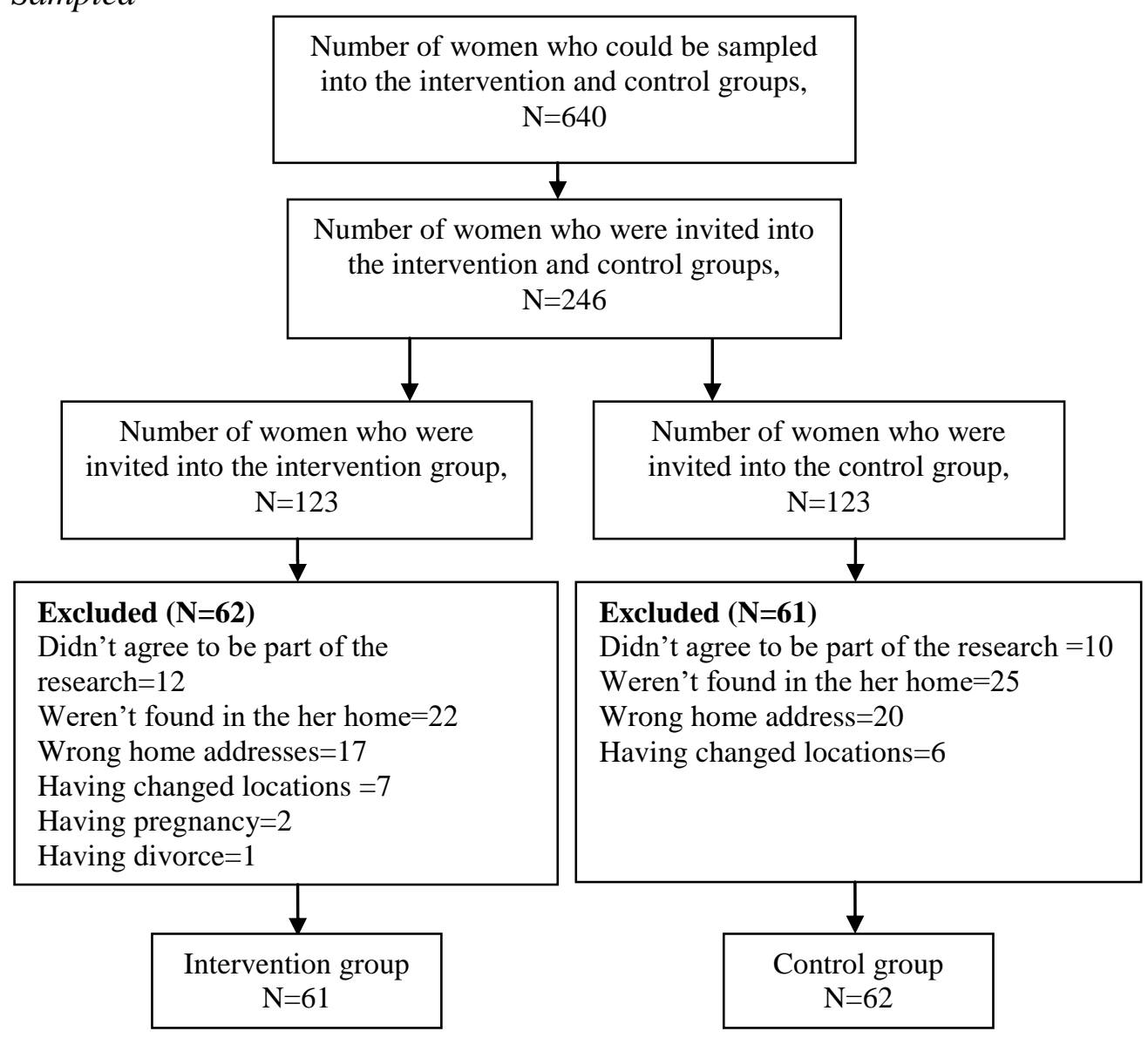

\section{Data Collection}

The survey data was developed by the researchers based on literature and collated through the use of a personal information form consisting of two sections: a birth and a postpartum sexual life questionnaire (Abdool et al. 2009, Acele and Karacam 2012, Barrett et al. 2000, Holanda et al. 2014, Johnson 2011), the Arizona Sexual Experiences Scale-Female Form, and the Sexual Quality of Life Questionnaire-Female Form.

The personal information form asked 19 questions about the woman's socio-demographic features. The questionnaire in relation with the prepregnancy, preganancy and postpartum period however asked 23 questions on obstetric histories, pre-pregnancy, pregnancy and the postpartum period; and about conditions that are considered risk factors for postpartum sexual life. To provide comprehension and perspective validity during the development of the questionnaire, a professional opinion was sought from 10 educationists from the areas of nursing involving the health and diseases of the birth-woman, mental health and public health. Additonally, to develop the comprehensibilty and applicabilty of these forms, they were firstly piloted with 10 women. Hence, 
based on the professional opinions and on the results from the preliminary test, some of the questions featured in the questionnaires were edited.

Arizona Sexual Experience Scale: The Arizona Sexual Experience Scale was developed by McGahuey et al. (2000) for the evaluation of sexual malfunctions. The Turkish version of this scale was created by Sokyan in 2004. There are separate forms for males and females, for this research, the female form was used. The female form consists of 5 six-point Likert-type self-report questions. This form determines sexual desire, arousal, vaginal wetness, the capacity to reach orgasm and the feeling of satisfaction after orgasm.

There are differernt points for each question, from 1 to 6 . Total score ranges from 5 to 30 . The sum of the scores obtained from the scale items, constitutes the total scale score and the cut-off score was reported as 11 . During the reliability study of the scale, Cronbach's alpha value was reported as 0.90 (Soykan 2004). This scale has been used in some earlier studies conducted in Turkey (Acele and Karaçam 2012, Gürkaş 2009, Karaçam 2008). Cronbach's alpha values of the scale in this study were calculated to be 0.75 and 0.76 in the first and second visits, respectively.

Sexual Quality Life Questionnaire: This scale was developed by Symonds et al. (2005) and its validity and reliability have been confirmed. It was adapted into Turkish by Tuğut and Gölbaş1 in 2010. This scale constitutes of 18 items which are easily applicable and can be easily answered. It is expected that the answers provided for this scale are based on one's sexual life during the previous four weeks. Being a six-Likert type of scale, each item is scored between 1-6: (1=totally agree, $2=$ agree to a large extent, $3=$ partly agree, $4=$ disagree in part, $5=$ disagree to a large extent, $6=$ strongly disagree). A total score which ranges from $18-108$ can be obtained from this scale. It is recommended that, in the evaluation of the questionnaire, raw scores obtained are firstly converted with this formula [Raw score obtained from scale-18) $\mathrm{x}$ 100/90] before used. For instance, an individual who obtains a raw score of 63 on the scale after conversion [(63-18)x100/90], gets 50. It has been shown that a high score obtained from this scale is analogous to a quality sexual life (Symonds et al. 2005). It is reported that during the adaptation of this scale into Turkish, the reliability coefficient of the entry total score changed to 0.32-0.67 while the Cronbach's $\alpha$ coefficient became 0.83 (Tuğut and Gölbaşı 2010). This scale has been used in some earlier studies conducted in Turkey (Kisa et al. 2014). Cronbach's alpha values of the Sexual Quality of Life scale in this study was calculated to be 0.78 and 0.77 after the first and second visits.

PLISSIT Model Intervention Plan: The Preparation of a Nursing Intervention Booklet for Sexual Probelms Experienced by Women During the Postpartum Period

The content of this booklet was prepared based on Annon's (1981) PLISSIT Model of Intervention. Also, by scanning related literature, necessary additional information related to the postpartum period was developed and converted into a beneficial booklet for the reseacher (Allen and Fountain 2007, 
Alteneder and Hartzell 1997, Dixon and Dixon 2006, Jaarsma et al. 2010, Johnson 2004, Hordern 2008). The following were captions which were featured in the booklet:

General information related to the postpartum period.

Changes which occured during the postpartum period.

$>$ A nursing intervention scheme for sexual probelms during the postpartum period.

$\checkmark$ Changes in sexual life during the postpartum period.

$\checkmark$ Sexual anxieties and problems.

$\checkmark$ Nursing interventions (PLISSIT Model).

- Permission $(\mathrm{P})$,

- Limited information (LI),

- Specific Suggestions (SS), and

- Intensive Therapy (IT).

Evaluation and results.

To provide reliability to the comprehension of the booklet, a professional opinion was sought from 5 doctors and nurses who have a postgraduate education in the areas of birth and female health and diseases. Reorganizations were done according to these opinions. To develop comprehensibility and applicability and also to standardise the researcher's intervention and other applications, a pilot study was carried out with 10 women. These women used for the pilot study were excluded from the main study.

\section{Procedure}

The random selection and determination of the addresses of the women who would be sampled, computer records from the Antalya Provincial Health Directorate and from the family doctors in the family health centres where the research was carried out were utilised. The women from both groups whose addresses defined were made the two times home visit with a month interval. During these visits, the women were interviewed one after the other for privacy reasons. The first visit to the women in the intervention group was carried out in three sessions. For the first session, the data was collected while during the second and third sessions the PLISSIT Model intervention plan was introduced. Explanations about these sessions are given below. The women in the control group were however made to fill out forms for data collection upon the second visit.

First visit (first session): In the course of the first visit to the birth house, there was familiarisation with women from both groups after which an orientation about this research was done. After the women gave both their verbal and written consent to the research, the researchers, by using a face-toface interview technique, facilitated filling the personal information form and the birth and postpartum sexual life questionnaire. Later, the Arizona Sexual Experiences Scale-Female Form and the Sexual Quality of Life Scale-Female 
Form were filled after clafications on how to fill them were made. This way, the visit was completed for the first group while a 10-15 minute break was allowed for the intervention group before starting the second session.

Intervention (first visit, second session): In this session with the intervention group, training and counseling were given to the women using the "PLISSIT Model Intervention Plan (nursing interventions for women' sexual problems in the postpartum period) Booklet". The first and second steps of the PLISSIT Model intervention plan were applied in this session. The administration of this step was completed in about 15-20 minutes. Before the third session, a 10-15-minute break was again given.

First visit (third session): In this session, the third and fourth steps of the PLISSIT Model intervention plan was implemented and a booklet was given to each of them. The administration of these steps lasted for about 15-20 minutes.

Second visit: During the second visit, women from both groups once again completed the Arizona Sexual Experiences Scale-Female Form and the Sexual Quality of Life Questionnaire-Female Form. This interview was completed approximately within 10-15 minutes. After the interview had been completed, the PLISSIT Model intervention plan was applied to the women in the control group and to the working group, and they were each given a booklet.

\section{Ethical Consideration}

The research protocol was approved by the Faculty of Medicine Ethics Committee of Akdeniz University. A written permission was taken from the Provincial Health Directorate of the Antalya Province of the Republic of Turkey to carry out this research in the Kepez District of Antalya Province. Research information on women enrolled in the study was given and a written consent was taken. Moreover, permision was recieved by e-mail from Prof. Dr. Atilla Soykan who adapted the Arizona Sexual Experiences Scale into Turkish and from Yrd. Doç. Dr. Zehra Gölbaşı and Arş. Gör. Nilüfer Tuğut who also adapted the Sexual Quality of Life Questionnaire into Turkish, in order to use them in the research.

\section{Data Analyses}

The data was analysed with SPSS 18 (PASW Inc., Chicago. IL. USA). Ttest and $\mathrm{X}^{2}$-test were used to compare intervention and control groups on age, spouse's age, education, spouse's education, employment status, social security, type of family, civil marriage, perceived level of income, duration of marriage, return to work, type of birthing, having any health problem, having any health problem of her baby, breastfeeding, experience of sexual problems before and during pregnancy. Also, to compare the points obtained from the Arizona Sexual Experiences Scale-Female Form and the Sexual Quality of Life Scale-Female Form for the intervention and control groups, the t-test and Mann-Whitney $U$ test were used. Before and after the intervention for the control and intervention groups, the Wilcoxon Signed Ranks test was used to 
compare the points obtained from the Arizona Sexual Experiences Scale-Fmale Form and the Sexual Quality of Life Scale-Female Form. Furthermore, the Cronbach Alpha values were calculated for the Arizona Sexual Experiences Scale-Female Form and the Sexual Quality of Life Scale-Female Form. The monthly income of these women for the month of September in 2011, for a 4person family, was classified among the circumscription of hunger and poverty (Turkey Worker Union Confederation 2011).

\section{Results}

Table 1, gives the data about the women in both the intervention and control groups and their respective recognised husbands. The average age of the women participating in the intervention group and that of the women in the control group was $27.87 \pm 4.87$ and $26.74 \pm$ 5:01 respectively. For women from both groups, their statistics with regard to their ages and spouses' age, education, and employment status, civil marriage, duration of marriage, social security, income level, and family type and whether they had returned to work were similar. Additionally, information on the number of pregnancies and living children, cases of unwanted and unplanned pregnancies in their previous pregnancies, delivery type, and availability of episiotomy/laceration for those who underwent vaginal delivery as well as information on sexual life for women in both groups were similar in terms of statistics. More women in the intervention group were reported to be living with sexual problems, compared to the women in the control group, as the statistics for sexual problems showed significant differences in the proportion of the pre-pregnancy period (intervention: 24.6\%; control 6.5\%) and pregnancy period (intervention: $52.5 \%$; control 25.8\%). 
Table 1. Descriptive Characteristics of Women in the Study and Control Groups $(N=123)$

\begin{tabular}{|c|c|c|c|}
\hline Characteristics & Intervention group $(\mathbf{N}=\mathbf{6 1})$ & Control Group (N=62) & t-test or $x^{2}$ (p-value) \\
\hline Age, year, mean $\pm S D \S$ & $27.87 \pm 4.87$ & $26.74 \pm 5.01$ & $-1.263(0.209)$ \\
\hline Spouse's age, year, mean $\pm S D$ & $31.54 \pm 4.53$ & $30.89 \pm 5.01$ & $-0.758(0.450)$ \\
\hline \multicolumn{4}{|l|}{ Education status, $n(\%)$} \\
\hline Primary school, $1^{\text {st }}$ phase (5 years) & $21(34.4)$ & $21(33.9)$ & \multirow[t]{4}{*}{$1.380(0.710)$} \\
\hline Primary school, $2^{\text {nd }}$ phase ( 8 years) & 17 (27.9) & $16(25.8)$ & \\
\hline High school & $14(23.0)$ & 19 (30.6) & \\
\hline University & $9(14.8)$ & $6(9.7)$ & \\
\hline \multicolumn{4}{|l|}{ Education status of spouse, $n(\%)$} \\
\hline Primary school, 1st phase (5 years) & $16(26.2)$ & $15(24.2)$ & \multirow[t]{4}{*}{$7.742(0.052)$} \\
\hline Primary school, 2nd phase ( 8 years) & $12(19.7)$ & 19 (30.6) & \\
\hline High school & $19(31.1)$ & $24(38.7)$ & \\
\hline University & $14(23.0)$ & $4(6.5)$ & \\
\hline No official marriage, $n(\%)$ & $2(3.3)$ & $2(3.2)$ & $0.000(0.987)$ \\
\hline Durtion of marriage, year, mean $\pm S D$ & $5.95 \pm 4.70$ & $5.96 \pm 4.48$ & $0.011(0.991)$ \\
\hline Employed, $n(\%)$ & $10(16.4)$ & $11(17.7)$ & $0.039(0.842)$ \\
\hline Employed spouses, $n$ (\%) & $61(100.0)$ & 61 (98.4) & \\
\hline Having social security, $n(\%)$ & $59(96.7)$ & $55(88.7)$ & $2.910(0.088)$ \\
\hline Living in the nuclear family, $n(\%)$ & $54(88.5)$ & $48(77.4)$ & $2.678(0.102)$ \\
\hline \multicolumn{4}{|l|}{ Income level**, $n(\%)$} \\
\hline Minimum wages and less & $4(6.5)$ & $3(4.8)$ & \multirow[t]{4}{*}{$2.299(0.513)$} \\
\hline $659 T L-902 T L$ & $10(16.4)$ & $11(17.7)$ & \\
\hline $903 T L-2939 T L$ & 37 (60.7) & $43(69.4)$ & \\
\hline 2940 TL and more & $10(16.4)$ & $5(8.1)$ & \\
\hline Have returned to work, $n(\%)($ Intervention, $n=10),($ Control, $n=11)$ & $4(36.4)$ & $7(63.6)$ & $1.173(0.279)$ \\
\hline \multicolumn{4}{|l|}{ Number of pregnancies, $n(\%)$} \\
\hline 1 & $27(44.3)$ & $23(37.1)$ & \multirow[t]{4}{*}{$2.697(0.441)$} \\
\hline 2 & $18(29.5)$ & $27(43.5)$ & \\
\hline 3 & $11(18.0)$ & $8(12.9)$ & \\
\hline $4-6$ & $5(8.2)$ & $4(6.5)$ & \\
\hline
\end{tabular}




\begin{tabular}{|c|c|c|c|}
\hline \multicolumn{4}{|l|}{ Number of live children, $n(\%)$} \\
\hline 1 & $28(45.9)$ & $26(41.9)$ & \multirow[t]{3}{*}{$0.214(0.898)$} \\
\hline 2 & $27(44.3)$ & $29(46.8)$ & \\
\hline 3 & $6(9.8)$ & $7(11.3)$ & \\
\hline Number of unplanned pregnancies, $n(\%)$ & $22(36.1)$ & $21(33.9)$ & $0.065(0.799)$ \\
\hline Number of unwanted pregnancies, $n(\%)$ & $6(9.8)$ & $4(6.5)$ & $0.472(0.492)$ \\
\hline \multicolumn{4}{|l|}{ Type of the birth, $n(\%)$} \\
\hline Vaginal & $19(31.1)$ & $17(27.4)$ & \multirow[t]{2}{*}{$0.206(0.650)$} \\
\hline Caesarean & $42(68.9)$ & $45(72.6)$ & \\
\hline $\begin{array}{l}\text { Having episiotomy/laceration, } n(\%) \text { (Intervention, } n=19) \text {, (Control, } \\
n=17)\end{array}$ & $18(94.7)$ & $14(82.4)$ & $1.393(0.238)$ \\
\hline Recieves information on sexual life, $n(\%)$ & $18(29.5)$ & $23(37.1)$ & $0.797(0.372)$ \\
\hline Sexual problems before pregnancy, $n(\%)$ & $15(24.6)$ & $4(6,5)$ & $7.745(0.005)$ \\
\hline Sexual problems during pregnancy, $n(\%)$ & $32(52.5)$ & $16(25.8)$ & $9.179(0.002)$ \\
\hline
\end{tabular}

Notes: $§$ Standard deviation.

* A literate spouse in the intervention group was included in the $1^{\text {st }}$ phase of elementary school.

** Those in the intervention and control group whose income was unknown, was spread across all the ranges given under minimum wages and below.

*** The monthly income of these women for the month of September in 2011, for a 4-person family, was classified among the circumscription of hunger and poverty (Turkey Worker Union Confederation 2011).

Source: Authors' estimations. 
In Table 2, data relating to the postpartum period for women in both the intervention and control groups is given. It is realised that, there are statistical similarites in the information given about the women in both groups regarding the average months of the postpartum period, breastfeeding, whether the mothers sleep in the same room with the baby and the availabilty of help for house chores. Again, there were statistical similarities in the time of resumption of regular menstruation after childbirth, the use of a family planning method, the existence of health problems in the women themselves or in their spouses and medication, the average time when they returned to their sexual life and the occurence of dyspareunia for women in both groups. Futhermore, it was statistically determined that some of the women in the intervention and control groups, had had similar exposure to the emotional, economic and physical violence and difficult sexual intercourses.

Table 2. Data on the Postpartum Period for Women in Intervention and Control Groups $(n=123)$

\begin{tabular}{|l|c|c|c|}
\hline Data & $\begin{array}{c}\text { Intervention } \\
\text { Group } \\
\text { (n=61) }\end{array}$ & $\begin{array}{c}\text { Control } \\
\text { Group } \\
\text { (n=62) }\end{array}$ & $\begin{array}{c}\text { t-test or } \mathbf{x}^{2} \\
\text { (p-value) }\end{array}$ \\
\hline Month of postpartum period, mean \pm SD & $8.49 \pm 6.61$ & $7.90 \pm 2.93$ & $-1.177(0.242)$ \\
\hline Breastfeeding, $\mathrm{n}(\%)$ & $52(85.2)$ & $44(71.0)$ & $3.659(0.056)$ \\
\hline Sleeping in the same room with child, $\mathrm{n}(\%)$ & $55(90.2)$ & $52(83.9)$ & $1.076(0.300)$ \\
\hline Havin a helper for house chores, $\mathrm{n}(\%)$ & $20(32.8)$ & $29(46.8)$ & $2.510(0.113)$ \\
\hline Having resumed menstruation, $\mathrm{n}(\%)$ & $24(39.3)$ & $33(53.2)$ & $2.383(0.123)$ \\
\hline Using contraceptives, $\mathrm{n}(\%)$ & $56(91.8)$ & $57(91.9)$ & $0.001(0.979)$ \\
\hline Having health problems, $\mathrm{n}(\%)$ & $9(14.8)$ & $9(14.5)$ & $0.001(0.970)$ \\
\hline Using medicine, $\mathrm{n}(\%)$ & $7(11.5)$ & $5(8.1)$ & $0.406(0.524)$ \\
\hline Spouse having health problems of, $\mathrm{n}(\%)$ & $11(18.0)$ & $5(8.1)$ & $2.700(0.100)$ \\
\hline Using medicine of spouse is, $\mathrm{n}(\%)$ & $7(11.5)$ & $4(6.5)$ & $0.953(0.329)$ \\
\hline The baby having health problems, $\mathrm{n}(\%)$ & $5(8.2)$ & $9(14.5)$ & $1.217(0.270)$ \\
\hline Time of return to sexual life, day, mean \pm SD & $52.54 \pm 20.28$ & $56.05 \pm 23.09$ & $0.895(0.373)$ \\
\hline $\begin{array}{l}\text { Experiencing dyspareunia after delivery, } \mathrm{n} \\
\text { (\%) }\end{array}$ & $11(18.0)$ & $18(29.0)$ & $2.065(0.151)$ \\
\hline Exposed to emotional abuse, $\mathrm{n}(\%)$ & $13(21.3)$ & $18(29.0)$ & $0.972(0.324)$ \\
\hline Exposed to economic abuse, $\mathrm{n}(\%)$ & $2(3.3)$ & $1(1.6)$ & $0.359(0.549)$ \\
\hline Exposed to physical abuse, $\mathrm{n}(\%)$ & $7(11.5)$ & $6(9.7)$ & $0.105(0.746)$ \\
\hline Exposed to sexual abuse, $\mathrm{n}(\%)$ & $4(6.6)$ & $5(8.1)$ & $0.103(0.748)$ \\
\hline
\end{tabular}

Note: * Standard deviation.

Source: Authors' estimations.

It was found that the average point of the pre-test for the women in the intervention group (63.03) was higher than that of the women in the control group (60.57), but this difference was not statistically significant. On the other hand, the average point for the post-test measured from the Arizona Sexual Experiences Scale for the women in the intervention group (60.57) was lower than that of the women in the control group, but the difference between groups was not statistically significant. In a similar way, the average points for both the study and the control groups for the pre-test (intervention: 62.47; control: 61.54) and post-test (intervention: 58.59; control: 65.35) using the Arizona Sexual Experiences Scale were described as similar to each other (Table 3 ). 
Table 3. Points Scored by Women in the Intervention Group and Control Group on the Arizona Sexual Experiences Scale-Female form and the Sexual Quality of Life Scale-Female Form before and after the Application of the PLISSIT Model Initiative Plan

\begin{tabular}{|c|c|c|c|}
\hline & $\begin{array}{c}\text { Intervention } \\
\text { Group } \\
(\mathbf{n}=61)\end{array}$ & $\begin{array}{l}\text { Control } \\
\text { Group } \\
(n=62)\end{array}$ & $\begin{array}{c}\mathbf{x}^{2} \text { or } U \\
\text { (p-value) }\end{array}$ \\
\hline \multicolumn{4}{|c|}{ Arizona Sexual Experiences Scale-Female form } \\
\hline Total point for pre-test, mean $\pm S D$ & $14.33 \pm 4.46$ & $13.84 \pm 4.17$ & $1828.000(0.749)$ \\
\hline \multicolumn{4}{|c|}{ Having sexual problems before intervention, $n(\%)$} \\
\hline Positive (12 points and above) & $47(77.0)$ & $44(71.0)$ & $0.591(0.442)$ \\
\hline Negative (11 points and below) & $14(23.0)$ & $18(29.0)$ & \\
\hline Total point for post-test, mean \pm SD & $13.62 \pm 4.26$ & $13.71 \pm 3.91$ & $1803.500(0.657)$ \\
\hline \multicolumn{4}{|c|}{ Having sexual problems after intervention, $n(\%)$} \\
\hline Positive (12 points and above) & $37(60.7)$ & $48(77.4)$ & $4.047(0.044)$ \\
\hline Negative (11 points and below) & $24(39.3)$ & $14(22.6)$ & \\
\hline \multicolumn{4}{|c|}{ Sexual Quality of Life Scale-Female Form } \\
\hline Total point for pre-test, mean $\pm S D$ & $77.18 \pm 10.71$ & $75.26 \pm 14.69$ & $1862.500(0.885)$ \\
\hline Total point for post-test, mean \pm SD & $76.57 \pm 11.37$ & $77.08 \pm 13.57$ & $1683.000(0.291)$ \\
\hline
\end{tabular}

Additionally, it was realised that before the application of the PLISSIT Model intervention plan, similar percentages of women; $77.0 \%$ in the intervention group and $71.0 \%$ in the control group were facing sexual problems as they scored 12 points or above on the female form of the Arizona Sexual Experiences Scale. However, after the application of the PLISSIT Model initiative plan, in a lesser proportion, $60.7 \%$ of the women in the intervention group as compared to $77.4 \%$ of those in the control group were facing sexual problems. This difference was significant to the statistical analysis (Table 3). In the comparison of the median scores from the pre-test and post-test of the Arizona Sexual Experiences Scale-Female Form and the Sexual Quality of Life Scale-Female Form for both groups, there were no statistically significant differences (Table 4 and Table 5).

Table 4. Points Scored by Women in the Control Group on the Arizona Sexual Experiences Scale-Female Form and the Sexual Quality of Life Scale-Female Form for the Pre-test and Post-tests

\begin{tabular}{|c|c|c|c|c|}
\hline & \multicolumn{4}{|c|}{ Control Group $(n=62)$} \\
\hline & \multicolumn{2}{|c|}{ ASES-FF* } & \multicolumn{2}{|c|}{ SQLS-FF** } \\
\hline & Pre-test & Post-test & Pre-test & Post-test \\
\hline Median & 14.00 & 14.00 & 68.89 & 71.11 \\
\hline Min-max & $5.00-23.00$ & $5.00-24.00$ & $18.89-91.11$ & 18.89-91.11 \\
\hline SD & 0.53 & 0.50 & 2.07 & 1.92 \\
\hline$Z$ (p-value) & \multicolumn{2}{|c|}{$-0.335(0.737)$} & \multicolumn{2}{|c|}{$-1.647(0.099)$} \\
\hline
\end{tabular}

Source: Authors' estimations. 
Table 5. Points Scored by Women in the Intervention Group on the Arizona Sexual Experiences Scale-Female Form and the Sexual Quality of Life Scale-Female Form for the Pre-test and Post-test

\begin{tabular}{|l|c|c|c|c|}
\hline \multirow{2}{*}{} & \multicolumn{4}{|c|}{ Intervention Group (n=61) } \\
\cline { 2 - 5 } & \multicolumn{2}{|c|}{ ASES-FF* } & \multicolumn{2}{c|}{ SQLS-FF** } \\
\cline { 2 - 5 } & Pre-test & Post-test & Pre-test & Post-test \\
\hline Median & 14.00 & 14.00 & 68.89 & 68.89 \\
\hline Min-max & $5.00-27.00$ & $6.00-27.00$ & $21.11-81.11$ & $16.67-80.00$ \\
\hline SD & 0.57 & 0.55 & 1.52 & 1.62 \\
\hline Z (p-value) & \multicolumn{2}{|c|}{$-1.969(0.049)$} & \multicolumn{2}{c|}{$-0.436(0.663)$} \\
\hline Note: * Arizona Sexual Experiences Scale-Female Form. \\
\multirow{2}{*}{ ** Sexual Quality of Life Scale-Female Form. }
\end{tabular}

\section{Discussion}

To examine the effectiveness of the PLISSIT Model in solving sexual problems experienced by women during the postpatum period a research which was carried out quasi-exprimentally regulated by a pre-test and a post-test with a control group was used. It was realised after the application of the PLISSIT Model intervention plan that fewer women in the intervention group as compared to the proportion of that of the control group were experiencing sexual problems. No study regarding the use of the PLISSIT Model intervention plan by women in their postpartum period was encountered during the evaluation of the literature. However it is reported that this model has had a positive effect on the development of the sexual function of individuals at various stages of life and in diverse situations (Ayaz and Kubilay 2008, Chun 2011, Jaarsma et al. 2010, Ju-Hee 2013, Lara et al. 2008, Rostamkhani et al. 2015, Tütüncü 2009). The fact that more women in the intervention group than in the control group had sexual problems before and during pregnancy and that the results for the pre-test indicate a higher percentage of women from the intervention group with sexual problems before the application of the PLISSIT Model could have limited the effectiveness of the model.

During this research, many factors which could affect the lives of the women in both the intervention and control groups were encountered, these put the women in similar circumstances. These factors included sociodemographic and obstretic features, type of birth, occurence of episiotomy/ spontaneous laceration, breastfeeding, existence of health problems in the baby, availability of a helper for house-hold chores, sleeping in the same room with the baby, regular menstruation, the time of return to sexual life, collection of information related to sexual life, the use of a family planning method, abuse within family, existence of health problems and the use of medicine. These results showed that these factors could have been ecountered and hence both groups could have been placed in the same circumstances. 
It was reported in various studies relating to the pre-pregnancy, pregnancy and postpartum period that the parameters and satisfaction level of one's sexual funtion was best before pregnancy and worst during pregnancy (Akyüz and Karaçam 2012, Barrett et al. 2000, Karaçam and Çalışır 2012, Oboro and Tabowei 2002, Olsson et al. 2005). Sexual problems experienced during pregnancy were usually due to fear of harming the fetus, the man's doubts about injuring the woman and the fear of inability of the woman to please the husband (Brtnicka et al. 2009). In this research, it was found that women in the intervention group had statistical significantly more sexual problems before and during pregnancy and encountered various situations which hindered sexual intercourse than women in the control group. This case may have affected the results of the research after applying the PLISSIT Model intervention plan.

Since thefemale form of the Arizona Sexual Experiences Scale does not ask whether or not the woman experiences dyspareunia during sexaul intercourse, the existence of dyspareunia in the postpartum period was determined by asking the question, "Have you been experiencing pain during sexual intercourse in the past week?". Women in the control group (29.0\%) reported statistical significantly more experiencing dyspareunia than women in the intervention group $(18.0 \%)$. This conclusion may have affected the degree of effectiveness of the PLISSIT Model intervention plan during the evaluation of the outcome of this intervention.

Before the application of the PLISSIT Model intervention plan, the median Arizona Sexual Experiences Scale-Female Form pre-test scores of the intervention group were smilar to the control group. Also, it was realised that there were similar frequencies for those in the intervention group and control group who obtained 12 points or above on the Arizona Sexual Experiences Scale-Female Form and hence were experiencing sexual probelms. These findings indicated that that women from both groups were in similar circumstances at the beginning of the research.

After the application of the PLISSIT Model intervention plan, the median Arizona Sexual Experiences Scale-Female Form and the Sexual Quality of Life Scale-Female Form post-test scores were lower in the intervention group than in the control group, but these differences were not significant statistically. On the other hand, when women participated in this study were evaluated on having 12 points or above from the Arizona Sexual Experiences Scale-female Scale and experiencing sexual problems, women in the intervention group $(60.7 \%)$ had significantly lower sexual problems than in the control group (77.4\%). These results indicated that the PLISSIT Model initiative plan had the limited impact on the reduction of sexual problems during the postpartum period. The outcome could be associated with lower pre-test scores in the intervention group than in the control group, although the women in the intervention and control groups were randomly assigned in the research. 


\section{Limitations}

There were some limitations during this reseach. First of all, the personal information form as well as the pre-pregnancy, pregnancy and postpartum form were filled using the face-to-face interview technique. Consequent to the featuring of questions concerning the woman's sexual life and her exposure to potential violence in these forms, the answers given probably did not reflect the womans actual condition. Therefore, the reliability of the data was limited by the accuracy of the information given by the interviewer. Secondly, the Arizona Sexual Experiences Scale-Female Form and the Sexual Quality of Life Scale-Female Form were filled using the self-report method. The data obtained from these scales could be different if filled under the supervision of a professional. Thirdly, since this research was supposed to be a postgraduate thesis, data collection and the intervention stage were conducted by a single researcher hence single or double-blinding was not possible. However, to control co-intervention biases, the main outcome measurement of this study was obtained by a selfreport scales (Arizona Sexual Experiences Scale-Female Form and Sexual Quality of Life Scale-Female Form).

\section{Conclusion and Recommendation}

Based on the results leading to the discovery of the limited impact the PLISSIT Model intervention plan has on the reduction of sexual probelms experienced by women during the postpartum period, it can be said that it is necessary that the research is carried out with different sample groups, a longer-term eductional programme is run together with spouses, a review is constantly done by caregivers and that the result is evaluated. It is also thought that it would be appropriate to intergrate the PLISSIT Model intervention plan into postpartum care services and that it would be better if this model could be applied by nurses and midwives who constantly provide care for women in the postpartum period. Taylor and Davis (2006) also proposed that nurses who provide primary healthcare could make use of an extended PLISSIT model during counselling on sexual health. In addition, it could be recommended that the PLISSIT model should be introduced to health workers during in-service training directed towards sexual problems encountered during the postpartum period and their treatment. It could be also recommended that researches compared PLISSIT, ALARM and BETTER models in solving the sexual problems of women in the postpartum period are prfomed.

\section{Acknowlegements}

This research was conducted as a thesis for a master's program in Adnan Menderes University, Institute of Health Sciences, Department of Obstetric Health and Nursing Graduate Studies. We would like to express 
our profound gratitude to the women who participated in this reaserch and to the doctors working in the family health centres under the Health Directorate of the Antalya Province.

\section{References}

Abdool Z, Thakar R, Sultan AH (2009) Postpartum female sexual function. European Journal of Obstetrics \& Gynecology and Reproductive Biology145(2): 133-137.

Acele EÖ, Karaçam Z (2012) Sexual problems in women during the first postpartum year and related conditions. Journal of Clinical Nursing 21(7-8): 929-937.

Allen L, Fountain L (2007) Addressing sexuality and pregnancy in childbirth education classes. The Journal of Perinatal Education 16(1): 32-36.

Alteneder RR, Hartzell D (1997) Addressing couples' sexuality concerns during the childbearing period: Use of the PLISSIT model. Journal of Obstetric, Gynecologic, \& Neonatal Nursing 26(6): 651-658.

Annon JS (1981) PLISSIT therapy. In RJ Corsini (eds.), Handbook of Innovative Psychotherapies. New York: Wiley \& Sons, p. 626-639.

Ayaz S, Kubilay G (2008) Effectiveness of the PLISSIT model for solving the sexual problems of patients with stoma. Journal of Clinical Nursing 18(1): 8998.

Barrett G, Pendry E, Peacock J, Victor C, Thakar R, Manyonda I (2000) Women's sexual health after childbirth. BJOG: An International Journal of Obstetrics and Gynaecology 107(2): 186-195.

Botros SM, Abramov Y, Miller JJ, Sand PK, Gandhi S, Nickolov A, Goldberg RP (2006) Effect of parity on sexual function: An identical twin study. Obstetrics \& Gynecology 107(4): 765-770.

Brtnicka H, Weiss P, Zverina J (2009) Human sexuality during pregnancy and the postpartum period. Bratislavské lekárske listy - Bratislava Medical Journal 110(7): 427-431.

Chun N (2011) Effectiveness of PLISSIT model sexual program on female sexual function for women with gynecologic cancer. Journal of Korean Academy of Nursing 41(4): 471-480.

Cleary V, McCarthy G, Hegarty J (2012) Development of an educational intervention focused on sexuality for women with gynecological cancer. Journal of Psychosocial Oncology 30(5): 535-555.

Dixon KD, Dixon PN (2006) The PLISSIT Model care and management of patients' psychosexual needs following radical surgery. Lippincott's Case Management 11(2): 101-106.

Gibbons L, Belizán J M, Lauer JA, Betrán AP, Merialdi M, Althabe F (2010) The Global Numbers and Costs of Additionally Needed and Unnecessary Caesarean Sections Performed per Year: Overuse as a Barrier to Universal Coverage. World Health Report, Background Paper, No 30. Geneva, Switzerland: World Health Organization.

Gürkaş Y (2009) Determining the effect of hysterectomy operation on sexual functions of women between the ages of 35 - 55 who had total hysterectomy operations due to benign reasons. Master Thesis. Trakya University Health Sciences Institute, Edirne, Turkey. 
Handa V (2006) Sexual function and childbirth. Seminars in Perinatology 30(5): 253-256.

Hipp LE, Kane Low L, van Anders SM (2012) Exploring women's postpartum sexuality: Social, psychological, relational, and birth-related contextual factors. The Journal of Sexual Medicine 9(9): 2330-2341.

Hisasue S-I, Kumamoto Y, Sato Y, Masumori N, Horita H, Kato R, Kobayashi K, Hashimoto K, Yamashita N, Itoh N (2005) Prevalence of female sexual dysfunction symptoms and its relationship to quality of life: A Japanese female cohort study. Urology 65(1): 143-148.

Holanda JBL, Abuchaim ESV, Coca KP, Abrao ACFV (2014) Sexual dysfunction and associated factors reported in the postpartum period. Acta Paulista de Enfermagem 27(6): 573-578.

Hordern A (2008) Intimacy and sexuality after cancer: A critical review of the literature. Cancer Nursing 31(2): 9-17.

Jaarsma T, Steinke EE, Gianotten WL (2010) Sexual Problems in Cardiac Patients: How to assess, when to refer. Journal of Cardiovascular Nursing 25(2): 159164.

Johnson BK (2004) Prostate cancer and sexuality: Implication for nursing. Geriatric Nursing 25(6): 341-347.

Johnson CE (2011) Sexual health during pregnancy and the postpartum. The Journal of Sexual Medicine 8(5): 1267-1284.

Ju-Hee N (2013) Effect of PLISSIT Model sexual health enhancement program for women with gynecologic cancer and their husbands. Journal of Korean Academy of Nursing 43(5): 681-689.

Karaçam Z (2008) Effects of episiotomy on postpartum sexual function. Hemşirelikte Araştırma ve Geliştirme Dergisi 10(1): 38-46.

Karaçam Z, Çalışır H (2012) The Prevalence of pre-pregnancy and postpartum dyspareunia in women giving birth for the first time and related factors. Journal of Anatolia Nursing and Health Sciences 15(3): 205-213.

Kisa S, Zeyneloğlu S, Yilmaz D, Güner T (2014) Quality of sexual life and its effect on marital adjustment of Turkish women in pregnancy. Journal of Sex \& Marital Therapy 40(4): 309-322.

Lamont J, Hamilton ON (2012) Female sexual health consensus clinical guidelines. Journal of Obstetrics and Gynaecology Canada 34(8): 769-775.

Lara LA, Rosa e Silva AC, Romao AP, Junqueira FR (2008) The assessment and management of female sexual dysfunction. The Revista Brasileira de Ginecologia e Obstetrícia 30(6): 312-321.

Lee J-T, Tsai J-L (2012) Transtheoretical model-based postpartum sexual health education program improves women's sexual behaviors and sexual health. The Journal of Sexual Medicine 9(4): 986-996.

McGahuey CA, Gelenberg AJ, Laukes CA, Moreno FA, Delgado PL, McKnight KM, Manber R (2000) The Arizona Sexual Experience Scale (ASEX): Reliability and validity. Journal of Sex \& Marital Therapy 26(1): 25-40.

Oboro V, Tabowei TO (2002) Sexual function after childbirth in Nigerian women. International Journal of Gynecology and Obstetrics 78(3): 249-250.

Olsson A, Lundqvist M, Faxelid E, Nissen E (2005) Women's thoughts about sexual life after childbirth: Focus group discussions with women after childbirth. Scandinavian Journal of Caring Sciences 19(4): 381-387.

Rostamkhani F, Jafari F, Ozgoli G, Shakeri M (2015) Addressing the sexual problems of Iranian women in a primary health care setting: A quasiexperimental study. Iranian Journal of Nursing and Midwifery Research 20(1): $139-146$. 
Salim NR, Gualda DMR (2010) Sexuality in the puerperium: The experience of a group of women. Revista da Escola de Enfermagem da USP 44(4): 888-895.

Serati M, Salvatore S, Siesto G, Cattoni E, Zanirato M, Khullar V, Cromi A, Ghezzi F, Bolis P (2010) Female sexual function during pregnancy and after childbirth. The Journal of Sexual Medicine 7(8): 2782-2790.

Shirvani MA, Nesami MB, Bavand M (2010) Maternal sexuality after child birth among Iranian women. Pakistan Journal of Biological Sciences 13(8): 385389.

Soykan A (2004) The reliability and validity of Arizona Sexual Experiences Scale in Turkish ESRD patients undergoing hemodialysis. International Journal of Impotence Research 16(6): 531-534.

Symonds T, Boolell M, Quirk F (2005) Development of questionnaire on sexual quality of life in women. Journal of Sex \& Marital Therapy 31(5): 385-397.

Şahin N (2009) Sexuality in postpartum women. Zeynep Kamil Tip Bülteni 40(3): 125-130.

Taylor B, Davis S (2006) Using the Extended PLISSIT model to address sexual healthcare needs. Nursing Standard 21(11): 35-40.

Tuğut N, Gölbaşı Z (2010) Cinsel Yaşam Kalitesi Ölçeği-Kadın Türkçe versiyonunun geçerlik ve güvenirlik çalışması. Cumhuriyet Medical Journal 32(2): 172-180.

Turkey Worker Union Confederation (2011) Retrieved from http://goo.gl/nS0sDO. [Accessed: 12 December 2011]

Tütüncü B (2009) The effect of sexuality education given in accordance PLISSIT model to women after hysterectomy. Master Thesis. Marmara University Health Sciences Institute, İstanbul, Turkey.

Williams A, Herron-Marx S, Hicks C (2007) The prevalence of enduring postnatal perineal morbidity and its relationship to perineal trauma. Midwifery 23(4): 392-403.

World Health Organization (2004) Sexual health-a new focus for World Health Organization. Geneva, Switzerland: World Health Organization. Retrieved from http://goo.gl/yrJDyU. [Accessed: 1 April 2015]

Xu XY, Yao ZW, Wang HY, Zhou Q, Zhang LW (2003) Women's postpartum sexuality and delivery types. Zhonghua Fu Chan Ke Za Zhi_38(4): 219-222. 
